\title{
Chest Pain on the Ward: A Simulation Scenario for Rural Family and Emergency Medicine Trainees
}

\author{
Kerry-Lynn Williams ${ }^{1}$, Paul Crocker ${ }^{2}$, Adam Dubrowski ${ }^{3}$ \\ 1. Family Medicine, Memorial University of Newfoundland, Happy Valley-Goose Bay, CAN 2. Family Medicine, \\ Memorial University, St. John's, CAN 3. Health Sciences, Ontario Tech University, Oshawa, CAN
}

Corresponding author: Kerry-Lynn Williams, kwilliams@mun.ca

\begin{abstract}
Chest pain is a frequently encountered emergency room presentation, of which about $15 \%$ of cases are due to acute coronary syndromes. Cardiogenic shock is a relatively uncommon complication with associated high morbidity and mortality. Emergency medicine practitioners frequently encounter critically ill patients that require quick, definitive treatment to optimize patient outcomes. These high acuity presentations often are of relatively low occurrence which makes training residents and learners challenging.
\end{abstract}

Simulation-based medical education has been shown to enhance patient outcomes by teaching these high acuity low occurrence (HALO) presentations in a safe environment. Herein we describe a simulation scenario of a patient with cardiogenic shock secondary to acute coronary syndrome. It consists of a step-wise, detailed summary of the case, along with modifiers to adjust the case for repeated use, learning objectives, and a suggested evaluation.

Categories: Emergency Medicine, Medical Education, Medical Simulation

Keywords: myocardial infarction, cardiogenic shock, simulation-based medical education, rural medicine, emergency medicine

\section{Introduction}

Ischemic heart disease (IHD) is the leading cause of death among adults in Canada, with more than 600,000 people dying annually [1]. Coronary artery disease (CAD) accounts for the vast majority of patients with IHD. The main symptom of CAD is chest pain, which results in over 8 million presentations to the emergency department annually [2]. Of those, approximately $15 \%$ have acute coronary syndrome (ACS), a third of whom have an acute myocardial infarction (MI) [3]. About $5-10 \%$ of patients with acute MI have cardiogenic shock, rendering it a rare but potentially lethal presentation.

Received 03/11/2020 Review began 06/15/2020 Review ended 06/16/2020 Published 06/28/2020

(c) Copyright 2020 Williams et al. This is an open access article distributed under the terms of the Creative Commons Attribution License CC-BY 4.0., which permits unrestricted use, distribution, and reproduction in any medium, provided the original author and source are credited.
Cardiogenic shock is the leading cause of in-hospital death in patients with acute MI [3] and seen in 4-8\% of patients with ST-segment elevation myocardial infarction (STEMI) [4]. Depending on the area and extent of infarct, mechanical complications, including rupture of the septum, ventricular wall, or chordae tendinae, may or may not be present [5]. It occurs less frequently in patients with non-ST-segment elevation myocardial infarction (NSTEMI). About $10 \%$ of acute MI patients who will develop cardiogenic shock have it at presentation, with the median onset after arrival being approximately six hours. Cardiogenic shock is associated with a mortality of about $40 \%$, with about half of the deaths occurring within the first 48 hours after presentation [6]. Therefore, early recognition of cardiogenic shock or ongoing myocardial ischemia is key for rural family medicine trainees. Early and effective management is key in restoring perfusion and optimizing patient outcomes.

People living in rural communities report higher levels of cardiovascular disease risk factors, including smoking, obesity, and inactivity compared to their urban counterparts. They also report higher levels of heart disease, hypertension, and stroke [7]. Due to a multitude of factors, cardiologists are less likely to establish a full-time practice in rural areas [8]. Consequently, rural patients have fewer overall visits to specialists and tend to rely heavily on care provided locally by primary care physicians. Predicting the clinical course in these critically ill patients can be quite challenging and determining whether a particular rural hospital has the capacity to care for such a patient is complex. Patients often want to remain local for treatment whenever possible, however, transport to a tertiary care centre sometimes becomes necessary [9].

Presently, teaching around this subject is largely didactic. Continuing medical education (CME) courses such as advanced cardiac life support (ACLS) offer a mix of didactic lessons and simulated cases. Simulationbased medical education has been repeatedly shown to affect learner skills, knowledge and attitudes, and patient outcomes [10]. It serves as a medium to teach high acuity low occurrence (HALO) and crisis resource management (CRM) skills and presentations in a safe environment. As such, it has become a mainstay of many postgraduate medical training programs. Recently, with the transition to the Competency by Design 
initiative for all Canadian postgraduate medical education programs, simulation will likely take a more predominant role in assessment.

This technical report is designed to train rural family and emergency medicine trainees in recognizing cardiogenic shock and quickly initiating the appropriate management steps. The objectives of this simulation scenario are:

1. Develop an approach to a patient with chest pain.

2. Communicate effectively with team members in the care of a complex, critically ill patient.

3. Recognize and manage evolving chest pain and cardiogenic shock.

4. Develop an approach to intubation in a patient with cardiogenic shock.

This report will be presented according to the Context-Inputs-Process-Product model [11].

\section{Technical Report}

\section{Context}

This simulation scenario was designed for the training of rural family or emergency medicine residents. However, any learner, rural or urban, who attends calls as part of a hospitalist rotation, whether undergraduate or postgraduate, may benefit from participation. It was designed to take place in a community hospital with no subspecialty backup in-house.

The scenario is run with the help of a confederate, an individual who, during the course of the scenario, provides assistance with equipment, provides information about the mannequin not available in other ways (e.g. temperature, colour change), and/or to provide additional realism by playing the role of a relative or staff member [12].

Three to four residents participate in the scenario, one as a team leader and the others in additional roles. If the scenario is run with only one resident, the resident is to assume the role of team leader and available confederates (e.g. nurses, respiratory therapists, other physicians, etc.) can be used as the additional team members.

\section{Inputs}

Personnel

Two facilitators, who were familiar with the scenario and its management, were present during the scenario. One ran the scenario, took notes, and provided prompts as needed. The other acted as a nurse confederate assisting with the scenario in order to meet the learning objectives. They performed tasks for the learners as requested and delivered results and prompts to the learners when needed. When fewer residents are available to partake in the simulation, more confederates may be used to assist the learners.

Equipment

The simulation session was conducted in a simulation lab using a Laerdal SimMan $3 \mathrm{G}^{\circledR}$ human patient simulator. The lab was outfitted with equipment, medications, and supplies typically available on a crash cart as well as those needed specifically for this case. The equipment and supplies are used only for simulation and teaching but are the same as what would be used in the hospital. The simulation lab is separate from the hospital and all equipment is clearly marked. The equipment provided included the following items:

- Advanced cardiac life support defibrillator and standard medications

- Airway supplies including oxygenation, intubation supplies, and suction

- Hospital chart and electrocardiograms (EKG)

- Intravenous (IV) access supplies and fluids

- Cardiac and oxygen monitors

- Medications, including vasopressors and inotropes 


\section{Cureus}

Higher fidelity simulation, defined as the level of realism associated with a particular simulation activity, is typically desirable. It is normally achieved by manipulating the realism of the simulator, the environment, or the scenario itself [13]. Lower fidelity simulators can be substituted for practice and integration into the scenario.

Process

One week prior to the session, a step-wise, detailed scenario template (Table 1) was generated and reviewed by the scenario facilitators. This allowed for programming of the mannequin as well as preparation of supporting materials for the scenario itself. In addition, this provided some time for the facilitators to review the scenario and complete a dry run of the scenario to identify any potential problem areas.

Pre-Briefing

A pre-briefing was held with all learners prior to the case. Learners were given a brief orientation to the simulation lab and mannequin. Limitations of simulation were reviewed, in particular addressing technical issues with the mannequin and resource availability. The fiction contract was addressed. This concept, also known as the "suspension of disbelief", encourages healthcare trainees and instructors to accept the simulation exercise as being real for the duration of the scenario in order to make it worthwhile [12]. Finally, learners were advised that the case was strictly formative.

Pre-scenario Information

You are a resident working overnight in the emergency department of your community hospital. A nurse from the inpatient ward comes to your office with an EKG from a patient who was admitted earlier in the day and is currently complaining of chest pain.

The Simulation

Table 1 depicts a step-wise, detailed scenario that was submitted to technical staff to run the simulation. Investigations that may be ordered, including EKG (Figure 1) and a chest radiograph (Figure 2) are provided upon learner request.

Nurse calls or presents with chart. Shows most recent EKG (Figure 1) and does not provide vitals.

2. Initial

assessment

RR: 28

SpO2: $91 \%$ RA

Patient alert and able to answer questions. Diaphoretic

$\mathrm{T}: 36.7^{\circ} \mathrm{C}$

HR: 110 bpm

3.

BP: $84 / 40$

\section{LEARNER ACTIONS}

OPERATOR NOTES

Ask nurse for vitals

Ask nurse for previous

EKG

As nurse for chart

Instruct nurse to place

patient on monitors

Go see patient

Get IV access

Apply oxygen

Draw bloodwork including VBG and troponin

EKG

Read through chart

Nitro spray $0.4 \mathrm{mg} \mathrm{SL}$

Q5min $\times 3$

No repeat EKG $\rightarrow$ Nurse to cue

Patient to cue still having chest pain after each spray of nitro

Triggers:

Nitro $\times 3 \rightarrow 3$. Deterioration

After 5 min nurse to cue patient looks more $\mathrm{SOB} \rightarrow 3$. Deterioration

Trial $250-500 \mathrm{~mL}$ crystalloid bolus

Repeat EKG, can consider 15 lead

Bolus given $\rightarrow$ BP 90/50

After 5 min, BP and SpO2 continue to trend down 


\section{Cureus}



\section{TABLE 1: Step-wise, detailed scenario template}

BIPAP - bilevel positive airway pressure; BP - blood pressure; bpm - beats per minute; CPR - cardiopulmonary resuscitation; CXR - chest radiograph; EKG - electrocardiogram; HR - heart rate; ICU - intensive care unit; IV - intravenous; min - minutes; Nitro - nitrogylcerin; NRB - nonrebreather; Q - every; RA - room air; RR - respiratory rate; RT - respiratory therapist; SL - sublingual; SOB - short of breath; SpO2 - oxygen saturation; T - temperature; VBG - venous blood gas; VT - ventricular tachycardia

\section{[14]."}

href="https://assets.cureus.com/uploads/figure/file/102987/lightbox_7015bee063c211eab97d8523d040a433ECG-Inferior-STEMI-Hyperacute-1.png">

title="EKG-showing-inferior-ST-elevation-myocardial-infarction-[14]." src="https://assets.cureus.com/uploads/figure/file/102987/article_river_7015bee063c211eab97d8523d040a433ECG-Inferior-STEMI-Hyperacute-1.png" />

FIGURE 1: EKG showing inferior ST elevation myocardial infarction[14].

Figure adapted from the website Life in the Fast Lane (https://litfl.com/) [14]. 


\section{Cureus}

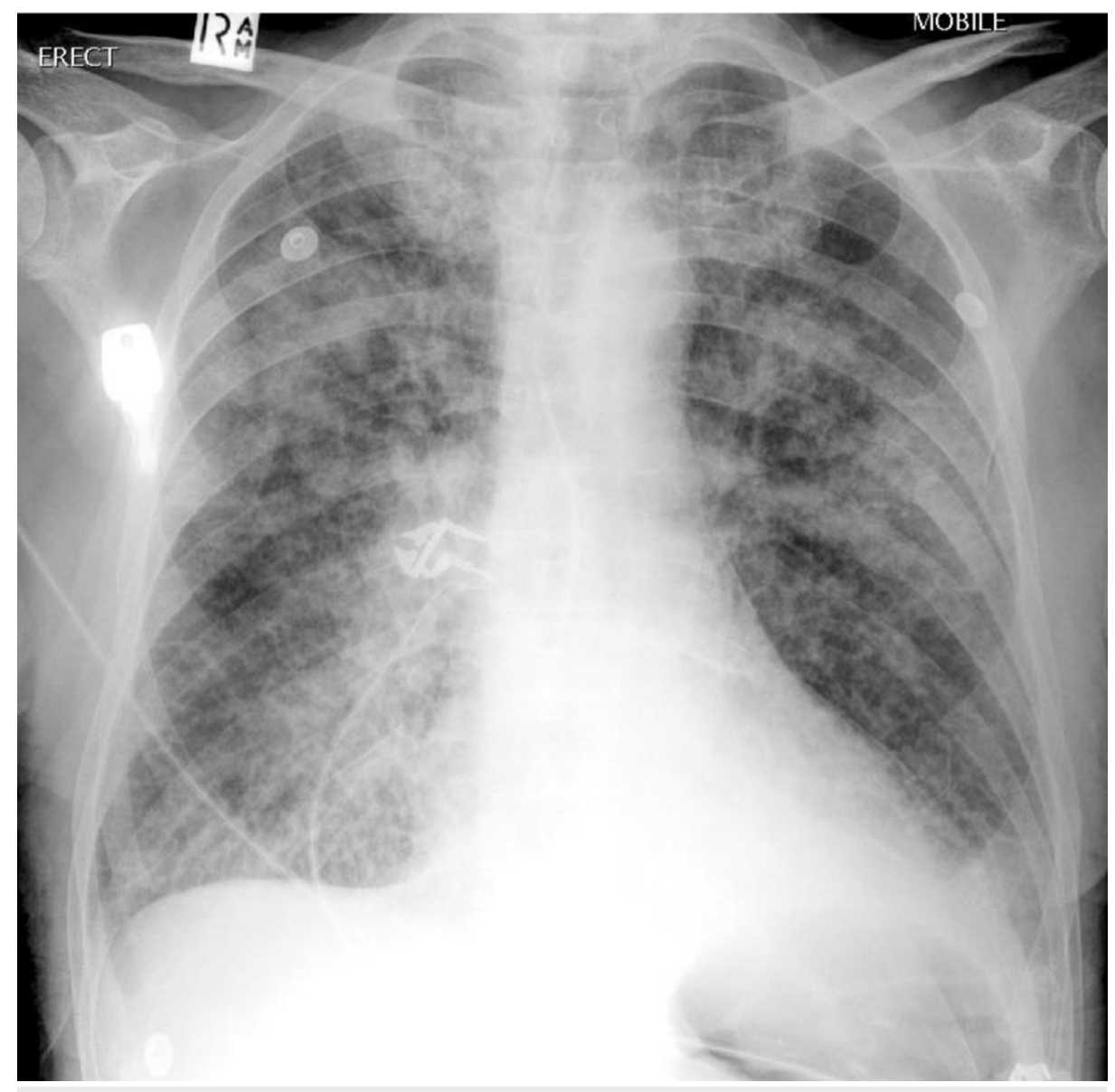

\section{FIGURE 2: Chest radiograph showing pulmonary edema}

Figure adapted from Radiopedia (radiopedia.org) [15] .

Debriefing and Post-Scenario Didactics

Following the conclusion of the scenario, facilitators and learners participated in a debriefing session. The debriefing was led by an experienced educator. Care was taken to ensure that the number of instructors to learners was approximately 1:1. Multiple debriefing models have been validated and choice usually is dictated by facilitator preference [16]. In this particular scenario, a modified plus/delta model was used [12]. Confederates and any simulated patients attended the start of the debriefing session to provide and receive feedback.

The content of the debriefing session was guided by the case learning objectives, yet it was a fluid process to accommodate the evolving dynamics of the team behaviour. That is, depending on how the scenario evolves, modifications were made to address any learning needs that arise. In this session, residents were taught around what to expect clinically from each infarct territory, the importance of serial EKGs, and the management of cardiogenic shock in the context of an acute MI. Considerations, such as the use of small boluses, vasopressor initiation, and when to consult a specialty service were also covered. The use and contraindications of TNK and intubation techniques were discussed. An approach to chest pain, including a differential diagnosis of non-cardiac causes of chest pain was also discussed. Additional objectives may be included by individual facilitators depending on local goals of the session. In cases such as this where transfer may be required, there is an opportunity to discuss local protocols and considerations such as weather and resource management.

Modifiers for the case can be applied in a variety of ways to both adjust difficulty and allow repeated use of the case, highlighting different points at each encounter. Some such modifications are included in Table 2. One such modification could include death as the end scenario. Currently, there exists much discussion about the benefits of including death as an outcome in simulation-based medical education [17-18]. Depending on learner objectives, facilitators could include an unsuccessful resuscitation as an optional end to the case. 


\section{Cureus}

Feature Modifier and Comments

Simulated patient confederates

Family member Distressed, emotional, interfering

Thrombolization

TNK

The decision can be made to include this or not based on local learning objectives (e.g. protocols or exclusion criteria)

Location

Remote nursing clinic

Could receive the call from a remote nursing clinic, making an assessment necessary through videoconference and have to run the code via telemedicine

\section{Ultrasound}

Bedside echo

Can be an additional teaching point on a standardized patient confederate

Transport

Medevac

Weather down, no immediate access

Transportation

considerations

Have to assemble and prepare equipment for transport

Simulation Outcome

Death as a potential endpoint

For the advanced learner. Facilitators should decide beforehand if this will be a specific outcome.

Code

discussion/Family Facilitators can decide beforehand if this will be a specific objective

meeting

\section{TABLE 2: Sample modifiers that could be incorporated in the scenario}

TNK - tenecteplase

A 90-minute didactic teaching session was also included to provide further teaching on topics relating to the case objectives. The incorporation of teaching following the simulation has been shown to be superior to pre-simulation instruction alone [10]. This was broken down into 45 minutes immediately following the scenario and an additional 45 minutes in a separate teaching session the following morning.

Product

The expected learning outcomes for each participant are outlined by the learning objectives for this case:

1. Develop an approach to a patient with chest pain

2. Communicate effectively with team members in the care of a complex, critically ill patient

3. Recognize and manage evolving chest pain and cardiogenic shock

4. Develop an approach to intubation in a patient with cardiogenic shock

Although this simulation was held as a formative session, a locally developed global rating scale was used to quantitatively assess the learning objectives. It is included in Table 3. 


\section{Cureus}

\begin{tabular}{|c|c|c|c|c|c|}
\hline & $\begin{array}{l}\text { Clearly below } \\
\text { expectations }\end{array}$ & & Acceptable pertormance & & $\begin{array}{l}\text { Performs above } \\
\text { expectations }\end{array}$ \\
\hline \multirow[b]{2}{*}{$\begin{array}{l}\text { Initial } \\
\text { management of } \\
\text { a patient with } \\
\text { chest pain }\end{array}$} & 1 & 2 & 3 & 4 & 5 \\
\hline & $\begin{array}{l}\text { Demonstrates } \\
\text { deficient knowledge } \\
\text { of acute cardiac } \\
\text { presentations } \\
\text { without recognizing } \\
\text { and correcting it. }\end{array}$ & $\begin{array}{l}\text { Weak } \\
\text { knowledge of } \\
\text { acute cardiac } \\
\text { presentations. } \\
\text { Made errors } \\
\text { but did not } \\
\text { recognize or } \\
\text { correct them. }\end{array}$ & $\begin{array}{l}\text { Competent performance } \\
\text { that indicates working } \\
\text { knowledge of ACS but } \\
\text { committed some minor } \\
\text { errors that were } \\
\text { recognized and corrected. }\end{array}$ & $\begin{array}{l}\text { performance that } \\
\text { indicates working } \\
\text { knowledge of ACS but } \\
\text { committed a minor } \\
\text { error or did not } \\
\text { recognize and initiate } \\
\text { treatment in a timely } \\
\text { manner. }\end{array}$ & $\begin{array}{l}\text { Quickly recognizes and } \\
\text { initiates appropriate } \\
\text { management of ACS. }\end{array}$ \\
\hline \multirow[b]{2}{*}{ Communication } & 1 & 2 & 3 & 4 & 5 \\
\hline & $\begin{array}{l}\text { Does not } \\
\text { communicate well } \\
\text { with team. Does not } \\
\text { acknowledge team } \\
\text { communication. } \\
\text { Does not use } \\
\text { directed verbal/non- } \\
\text { verbal } \\
\text { communication. }\end{array}$ & $\begin{array}{l}\text { Weak } \\
\text { communication } \\
\text { with team. } \\
\text { Vague and } \\
\text { unclear team } \\
\text { communication. } \\
\text { Weak directed } \\
\text { verbal/non- } \\
\text { verbal } \\
\text { communication. }\end{array}$ & $\begin{array}{l}\text { Communicates mostly with } \\
\text { team, but unclear and } \\
\text { vague at times. Usually } \\
\text { uses directed verbal/non- } \\
\text { verbal communication. }\end{array}$ & $\begin{array}{l}\text { with team, but } \\
\text { occasionally is vague } \\
\text { or unclear. Usually } \\
\text { uses closed-loop } \\
\text { communication. } \\
\text { Usually uses directed } \\
\text { verbal/non-verbal } \\
\text { communication. }\end{array}$ & $\begin{array}{l}\text { Exemplary closed-loop } \\
\text { communication with team. } \\
\text { Consistently uses directed } \\
\text { verbal/non-verbal } \\
\text { communication. }\end{array}$ \\
\hline \multirow[b]{2}{*}{$\begin{array}{l}\text { Management of } \\
\text { cardiogenic } \\
\text { shock }\end{array}$} & 1 & 2 & 3 & 4 & 5 \\
\hline & $\begin{array}{l}\text { Demonstrates } \\
\text { deficient knowledge } \\
\text { of cardiogenic shock } \\
\text { without recognizing } \\
\text { and correcting it. }\end{array}$ & $\begin{array}{l}\text { knowledge of } \\
\text { cardiogenic } \\
\text { shock. Made } \\
\text { errors without } \\
\text { recognizing or } \\
\text { correcting } \\
\text { them. }\end{array}$ & $\begin{array}{l}\text { Competent performance } \\
\text { that indicates working } \\
\text { knowledge of cardiogenic } \\
\text { shock but committed } \\
\text { some minor errors that } \\
\text { were recognized and } \\
\text { corrected. }\end{array}$ & $\begin{array}{l}\text { Competent } \\
\text { performance that } \\
\text { indicates working } \\
\text { knowledge of } \\
\text { cardiogenic shock but } \\
\text { management could be } \\
\text { improved. }\end{array}$ & $\begin{array}{l}\text { Quickly recognizes and } \\
\text { initiates appropriate } \\
\text { management of cardiogenic } \\
\text { shock. }\end{array}$ \\
\hline \multirow[b]{2}{*}{$\begin{array}{l}\text { Intubation: } \\
\text { Organization } \\
\text { and selection } \\
\text { of supplies }\end{array}$} & 1 & 2 & 3 & 4 & 5 \\
\hline & $\begin{array}{l}\text { correct materials } \\
\text { and/or instruments } \\
\text { for task. Does not } \\
\text { organize } \\
\text { appropriately prior to } \\
\text { starting task. Does } \\
\text { not take into account } \\
\text { back up ventilation. }\end{array}$ & $\begin{array}{l}\text { Selects some } \\
\text { appropriate } \\
\text { materials but } \\
\text { forgets others. } \\
\text { Unorganized } \\
\text { approach. } \\
\text { Minimal backup } \\
\text { plan. }\end{array}$ & $\begin{array}{l}\text { materials. Organizes them } \\
\text { but not in a manner that } \\
\text { helps improve efficiency } \\
\text { with performing task or has } \\
\text { some materials but not } \\
\text { organized before } \\
\text { performance of the task } \\
\text { begins. }\end{array}$ & $\begin{array}{l}\text { materials and } \\
\text { instruments for task. } \\
\text { Mostly organized. } \\
\text { Back-up plan } \\
\text { considered. Could } \\
\text { improve on time or } \\
\text { organization but } \\
\text { competent. }\end{array}$ & $\begin{array}{l}\text { instruments for task. } \\
\text { Organizes in a deliberate } \\
\text { manner that facilitates task. } \\
\text { Materials are ready before } \\
\text { performance of task begins. } \\
\text { Has a back-up ventilation } \\
\text { plan ready. }\end{array}$ \\
\hline \multirow[b]{2}{*}{$\begin{array}{l}\text { Intubation: } \\
\text { Correct use of } \\
\text { instruments }\end{array}$} & 1 & 2 & 3 & 4 & 5 \\
\hline & $\begin{array}{l}\text { Student may use an } \\
\text { instrument } \\
\text { incorrectly and does } \\
\text { not correct mistake. }\end{array}$ & $\begin{array}{l}\text { use an } \\
\text { instrument } \\
\text { incorrectly and } \\
\text { may correct } \\
\text { mistake or } \\
\text { vocalize the } \\
\text { error. }\end{array}$ & $\begin{array}{l}\text { Student uses instrument } \\
\text { correctly for most part. } \\
\text { Occasional errors are } \\
\text { made but awareness and } \\
\text { correction is } \\
\text { demonstrated. }\end{array}$ & $\begin{array}{l}\text { uses instruments } \\
\text { correctly. Technique } \\
\text { mostly smooth, could } \\
\text { use some minor } \\
\text { suggestions. No } \\
\text { errors in use or } \\
\text { handling occur. }\end{array}$ & $\begin{array}{l}\text { Student holds and uses } \\
\text { instruments correctly } \\
\text { throughout using proficient } \\
\text { and smooth technique. No } \\
\text { errors in use or handling } \\
\text { occur. }\end{array}$ \\
\hline
\end{tabular}

\section{TABLE 3: Locally-developed global rating scale}

ACS - acute coronary syndrome 
Following the scenario, an anonymous survey is circulated to all participants. This allows the facilitators to gather feedback from the participants over the next few days following the session. Examples of questions circulated are included in Table 4.

Post-Scenario Survey Questions

Level of training

What did you like today?

What worked well?

What didn't work as well?

Did you find the simulation realistic?

Suggestions for future simulations/skill sessions?

TABLE 4: Post-scenario survey questions

\section{Discussion}

In over $70 \%$ of cases, cardiogenic shock is related to acute myocardial infarction with ST-segment elevation. The management of acute MI with or without cardiogenic shock is crucial for anyone practicing acute care medicine - both in rural and urban centres.

For example, medical trainees across multiple disciplines often have to complete off-service rotations in which on-call coverage of a medical floor is necessary. Therefore, the quick recognition and management of acute coronary syndrome, including acute myocardial infarction and cardiogenic shock is imperative.

Physicians practicing in rural locations tend to have broad scopes of practice and as such are responsible for managing such presentations until transfer to a tertiary care centre can be arranged [19-20]. Local considerations, such as weather, mode of transport, and resource availability become important and are easily included in the scenario.

This scenario was initially run in small groups (three to four learners per session) of rural family medicine residents and medical students. Scenario subject and learning objectives were not distributed prior to the session. Learners were encouraged to use any available resources - including books, ACLS algorithms, and web applications - during an emergency department or call shift. The didactic session focused largely on the aforementioned learning objectives, and a written handout was circulated to learners following the session. A second teaching session, within the subsequent two weeks, was held to incorporate some Point of Care Ultrasound (PoCUS) teaching around echocardiography. Feedback on the scenario was largely positive, in particular surrounding the management of cardiogenic shock. There were suggestions around in situ simulation of this case rendering it more realistic, but unfortunately, that was not possible at the time of the sessions. Instead, future sessions will incorporate some other allied health care professionals (including nursing and respiratory therapy) to work on team functioning along with the scenario.

Future work includes validation of the locally developed GRS as the simulation is repeated over time with different learners. This would allow for the provision of objective feedback to the learner in a structured approach. As well, this scenario is a part of a larger curriculum developed for rural and remote trainees and will evolve as required to reflect local learning objectives.

The development of this scenario in a step-wise fashion allows the simulation to react according to learner actions. The list of modifiers included in Table 2 allows for an easily adaptable scenario that can be repeated according to local learning objectives. Having a facilitator review the scenario in advance ensures that it is of reasonable difficulty for the intended learner group and allows instructors to identify any shortcomings of the scenario. Finally, the coupling of a formal debriefing with a didactic learning session allows for both the collaborative identification of knowledge gaps and process errors that may arise during the scenario.

\section{Conclusions}

The use of simulation in teaching rural medicine trainees to manage acute myocardial infarction and cardiogenic shock may close a learning gap. These situations can be very demanding and emotionally charged. Therefore, practice in a controlled environment can be beneficial for rural family medicine trainees, ultimately improving both learner comfort and patient outcomes. We have presented herein an acute STEMI with cardiogenic shock, along with scenario modifiers, and post-scenario didactics and 


\section{Additional Information \\ Disclosures}

Human subjects: Consent was obtained by all participants in this study. Animal subjects: All authors have confirmed that this study did not involve animal subjects or tissue. Conflicts of interest: In compliance with the ICMJE uniform disclosure form, all authors declare the following: Payment/services info: All authors have declared that no financial support was received from any organization for the submitted work. Financial relationships: All authors have declared that they have no financial relationships at present or within the previous three years with any organizations that might have an interest in the submitted work. Other relationships: All authors have declared that there are no other relationships or activities that could appear to have influenced the submitted work.

\section{References}

1. Benjamin EJ, Muntner P, Alonso A, et al.: Heart disease and stroke statistics-2019 update: a report from the American Heart Association. Circulation. 2019, 139:e56-528. 10.1161/CIR.0000000000000659

2. NCHS Data Brief. Prevalence of uncontrolled risk factors for cardiovascular disease: United States, 19992010. (2012). Accessed: May 9, 2019: https://www.cdc.gov/nchs/data/databriefs/db103.pdf.

3. Hollander JE, Diercks DB: Acute coronary syndromes. Tintinalli's Emergency Medicine: A Comprehensive Study Guide, 8th ed. Tintinalli JE (ed): McGraw Hill Education, New York; 2016. 332-352.

4. Aissaoui N, Puymirat E, Tabone X, et al.: Improved outcome of cardiogenic shock at the acute stage of myocardial infarction: a report from the USIK 1995, USIC 2000, and FAST-MI French Nationwide Registries. Eur Heart J. 2012, 33:2535-43. 10.1093/eurheartj/ehs264

5. Levy B, Bastien O, Karim B, et al.: Experts' recommendations for the management of adult patients with cardiogenic shock. Ann Intensive Care. 2015, 5:52. 10.1186/s13613-015-0052-1

6. Thiele H, Akin I, Sandri M, et al.: PCI strategies in patients with acute myocardial infarction and cardiogenic shock. N Engl J Med. 2017, 21:2419-2432. 10.1056/NEJMoa1710261

7. Gruca TS, Pyo TR, Nelson GC: Providing cardiology care in rural areas through visiting consultant clinics . J Am Heart Assoc. 2018, 5:002909. 10.1161/JAHA.115.002909

8. Rao MB, Lerro C, Gross CP: The shortage of on-call surgical specialist coverage: a national survey of emergency department directors. Acad Emerg Med. 2010, 17:1374-1382. 10.1111/j.1553-2712.2010.00927.x

9. Mohr NM, Wong TS, Faine B, et al.: Discordance between patient and clinician experiences and priorities in rural interhospital transfer: a mixed methods study. J Rural Health. 2016, 32:25-34. 10.1111/jrh.12125

10. Motola I, Devine LA, Chung HS, et al.: Simulation in healthcare education: A best evidence practical guide. AMEE Guide No 82. Med Teach. 2013, 10:e1511-30. 10.3109/0142159X.2013.818632

11. Stufflebeam DL: Evaluation checklists: practical tools for guiding and judging evaluations . Am J Eval. 2001, 22:71-79. 10.1177/109821400102200107

12. Lioce L, Lopreiato J, Downing D, et al.: Healthcare Simulation Dictionary, 2nd ed. Lioce L (ed): Agency for Healthcare Research and Quality, Rockville, MD; 2020.

13. INACSL Standards Committee: INACSL standards of best practice: Simulation Simulation design . Clin Simul Nurs. 2016, 12:S5-12. 10.1016/j.ecns.2016.09.005

14. Life in the Fast Lane. Inferior STEMI. (2019). Accessed: May 23, 2019: https://litfl.com/inferior-stemi-ecglibrary/.

15. Radiopedia. Acute pulmonary edema . (2017). Accessed: June 16, 2020: https://radiopaedia.org/cases/apoarrowsjpg.

16. Gardner R: Introduction to debriefing. Sem Perinatol. 2013, 37:166-174. 10.1053/j.semperi.2013.02.008

17. Corvetto MA, Taekman JM: To die or not to die? A review of simulated death . Simul Healthc. 2013, 8:8-12. 10.1097/SIH.0b013e3182689aff

18. Park CH, Wetmore D, Katz D, DeMaria S, Levine AI, Goldberg AT: Simulated death enhances learner attitudes regarding simulation. BMJ Simul Technol Enhanc Learn. 2018, 4:23-26. 10.1136/bmjstel-2017000215

19. Subedi R, Greenberg TL, Roshanafshar S: Does geography matter in mortality? An analysis of potentially avoidable mortality by remoteness index in Canada. Health Rep. 2019, 30:3-15. 10.25318/82-003x201900500001-eng

20. White D: Development of a rural health framework: Implications for program service planning and delivery . Healthc Policy. 2013, 8:27-41. 